Профиль микроРНК в адипоцитах и макрофагах человека при воспалении

\title{
Profile of microRNAs in human adipocytes and macrophages in inflammation
}

Shvangiradze T.A.

Endocrinology Research Centre, Dmitriya Ulyanova st., 11, Moscow, Russia, 117036

DOI: 10.14341/OMET2015353

Все чаще в мировой литературе обсуждается актуальность определения микроРНК в жировой ткани как участника различных биологических процессов, в том числе, и ассоциированного с ожирением воспаления. При ожирении жировая ткань является источником хронического воспалительного процесса, способствующего поддержанию инсулинорезистентности путем секреции ряда гормонов, адипокинов, жирных кислот и, вероятно, ряда микроРНК. Дифференцированные адипоциты секретируют множество воспалительных цитокинов и хемокинов (т.н. адипокинов) в ответ на активацию макрофагов. В то же время, снижение массы тела сопровождается уменьшением инфильтрации жировой ткани макрофагами в сочетании с редукцией экспрессии провоспалительных генов. МикроРНК - это маленькие не кодирующие РНК, способные стимулировать экспрессию генов путем репрессии трансляции генов-мишеней.

В своем исследовании Ortega F.J. и соавт. стремились охарактеризовать изменения микроРНК адипоцитов и макрофагов человека, сопровождающие воспалительный процесс. Была определена экспрессия 754 зрелых микроРНК в дифференцированных адипоцитах подкожно-жировой клетчатки человека и макрофагоподобных клетках линии ТНР-1 (М-1) исходно и при воспалении. МикроРНК, продемонстрировавшие наиболее значимые изменения, были исследованы в подкожной жировой ткани человека до и примерно через 2 года после потери веса вследствие проведенной бариатрической операции.

В дифференцированных адипоцитах была выявлена экспрессия 169 микроРНК, 85 из которых были обнаружены в надосадочной жидкости суспензии из клеток адипоцитов. В М-1 макрофагах были обнаружены 183 микроРНК, из них 106 также присутствовали в надосадочной жидкости этих клеток.
Воспаление приводило к увеличению числа обнаруживаемых микроРНК в клетках и надосадочной жидкости суспензии из этих клеток, как в адипоцитах $(+8,3 \%$ и $+24,7 \%)$, так и М-1 макрофагах $(+1,4 \%$ и $+5 \%$ соответственно). Под влиянием воспалительного процесса адипоциты и М-1 макрофаги экспрессировали 147 (+9\%) схожих микроРНК, и $100(+41 \%)$ микроРНК были общими для надосадочной жидкости суспензии из их клеток. Следует отметить, что микроРНК-221 (в 2 раза, $\mathrm{p}=0,002)$, микроРНК-222 (в 2,5 раза, $\mathrm{P}=0,04)$ и микроРНК-155 (5-кратно, $\mathrm{P}=0,015)$ были увеличены в воспаленных адипоцитах и в их надосадочной жидкости (15-, 6- и 4-кратно соответственно, все $\mathrm{p}<0,001)$. Кроме того, их экспрессия в жировой ткани человека значимо уменьшалась после снижения массы тела после бариатрической операции $(-51 \%, p=0,003,-49 \%, p=0,03$ и $-54,4 \% ; p=0,005$ соответственно).

Полученные Ortega F.J. и соавт. результаты показали, что воспалительный процесс способствует изменению профиля микроРНК в адипоцитах и макрофагах. Под воздействием воспаления увеличивалось и количество определяемых микроРНК как в адипоцитах и макрофагах, так и в жидкой части их суспензии. Не исключается, что микроРНК могут оказывать регуляторное воздействие на соседние клетки, в т.ч. осуществляя паракринную регуляцию.

Понимание экспрессии профилей микроРНК, связанных с различными состояниями адипоцитов и активацией макрофагов, может обеспечить новый спектр биомаркеров и терапевтических подходов к снижению инфильтрации макрофагами жировой ткани при ожирении и в дебюте ассоциированного с ним воспаления, а также в профилактике и лечении инсулинорезистентности и других ассоциированных заболеваний. 